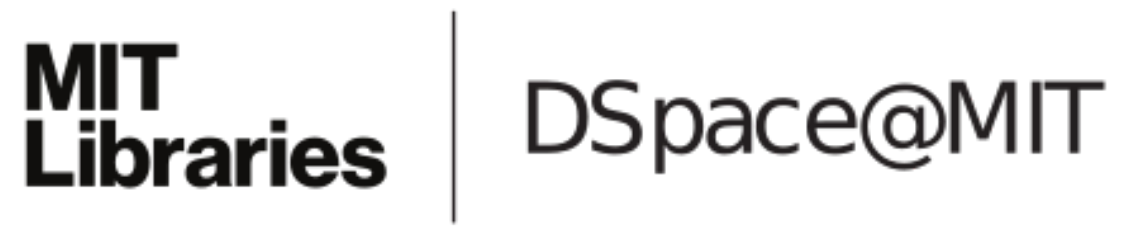

\author{
MIT Open Access Articles
}

Stakeholder and Constraint-Driven Innovation of a Novel, Lever-Propelled, All-Terrain Wheelchair

The MIT Faculty has made this article openly available. Please share how this access benefits you. Your story matters.

Citation: Winter, Amos G. “Stakeholder and Constraint-Driven Innovation of a Novel, LeverPropelled, All-Terrain Wheelchair." Volume 5: 25th International Conference on Design Theory and Methodology; ASME 2013 Power Transmission and Gearing Conference (August 4, 2013). (C) 2013 ASME International

As Published: http://dx.doi.org/10.1115/DETC2013-12588

Publisher: ASME International

Persistent URL: http://hdl.handle.net/1721.1/109236

Version: Final published version: final published article, as it appeared in a journal, conference proceedings, or other formally published context

Terms of Use: Article is made available in accordance with the publisher's policy and may be subject to US copyright law. Please refer to the publisher's site for terms of use. 
August 4-7, 2013, Portland, Oregon, USA

\title{
DETC2013-12588
}

\section{STAKEHOLDER AND CONSTRAINT-DRIVEN INNOVATION OF A NOVEL, LEVER-PROPELLED, ALL-TERRAIN WHEELCHAIR}

\author{
Amos G. Winter, $V^{*}$ \\ Department of Mechanical Engineering \\ Massachusetts Institute of Technology \\ Cambridge, Massachusetts 02139 \\ Email: awinter@mit.edu
}

\begin{abstract}
The Leveraged Freedom Chair (LFC) is a low-cost, allterrain, lever-propelled wheelchair designed primarily for use in developing countries. LFC technology was conceived because 70 percent of wheelchair users in these markets live in rural areas and no currently available mobility aid enables them to travel long distances on rough terrain and maneuver in tight, indoor confines. Because developing world markets impose constraints on cost, durability, and performance, a novel solution was required to satisfy stakeholder requirements. The key innovation behind the LFC is its single speed, variable mechanical advantage lever drivetrain. The user effectively changes gear by shifting his hands along the levers; grasping near the ends increases torque, while grasping near the pivots enables a larger angular displacement with every stroke, which increases speed. The drivetrain is made from low-cost bicycle parts found throughout the developing world, which enables the LFC to be sold for $\$ 200$ and be repairable anywhere.

During three user trials in East Africa, Guatemala, and India, stakeholder feedback was used to refine the chair between trials, resulting in a device $9.1 \mathrm{~kg}(20 \mathrm{lbs})$ lighter, $8.9 \mathrm{~cm}$ (3.5 in) narrower, and with a center of gravity $12.7 \mathrm{~cm}$ (5 in) lower than the first iteration. Survey data substantiated increases in performance after successive iterations. Quantitative biomechanical performance data were also measured during the Guatemala and India trials, which showed the LFC to be 76 percent faster and 41 percent more efficient during a common daily commute, and able
\end{abstract}

\footnotetext{
*Address all correspondence to this author.
}

to produce 53 percent higher peak propulsion force compared to conventional, pushrim-propelled wheelchairs. The LFC offers comparable performance at less than one-twentieth the cost of off road wheelchairs available in the rich world. Stakeholder feedback and the highly-constrained environment for which the LFC was created drove the technology towards a novel, innovative solution that offers a competitive advantage in both developing and developed markets. The paper concludes with a description of how the LFC is a "constraint-driven innovation." This idea ties together the theories of "disruptive innovation" and "reverse innovation," and may be used as a design tool for engineers striving to create technologies that have global impact.

\section{INTRODUCTION}

The Leveraged Freedom Chair (LFC) is a lever-propelled mobility aid designed for use on the varied terrain encountered in developing countries. The motivation behind the LFC project is to create a single mobility aid that can fully meet the usage needs, both indoors and outdoors and in terms of seating and postural support, of people with disabilities in developing countries and that transcends the capabilities of currently available products. The most common mobility aids in the developing world are conventional, pushrim-propelled wheelchairs (Fig. 17A) and handpowered tricycles (Fig. 11B). Pushrim-propelled wheelchairs are inefficient to propel [1] and are exhausting to use for long distances on rough roads. Hand-powered tricycles, which are preferred if the user has adequate torso stability [2, 3], are more ef- 


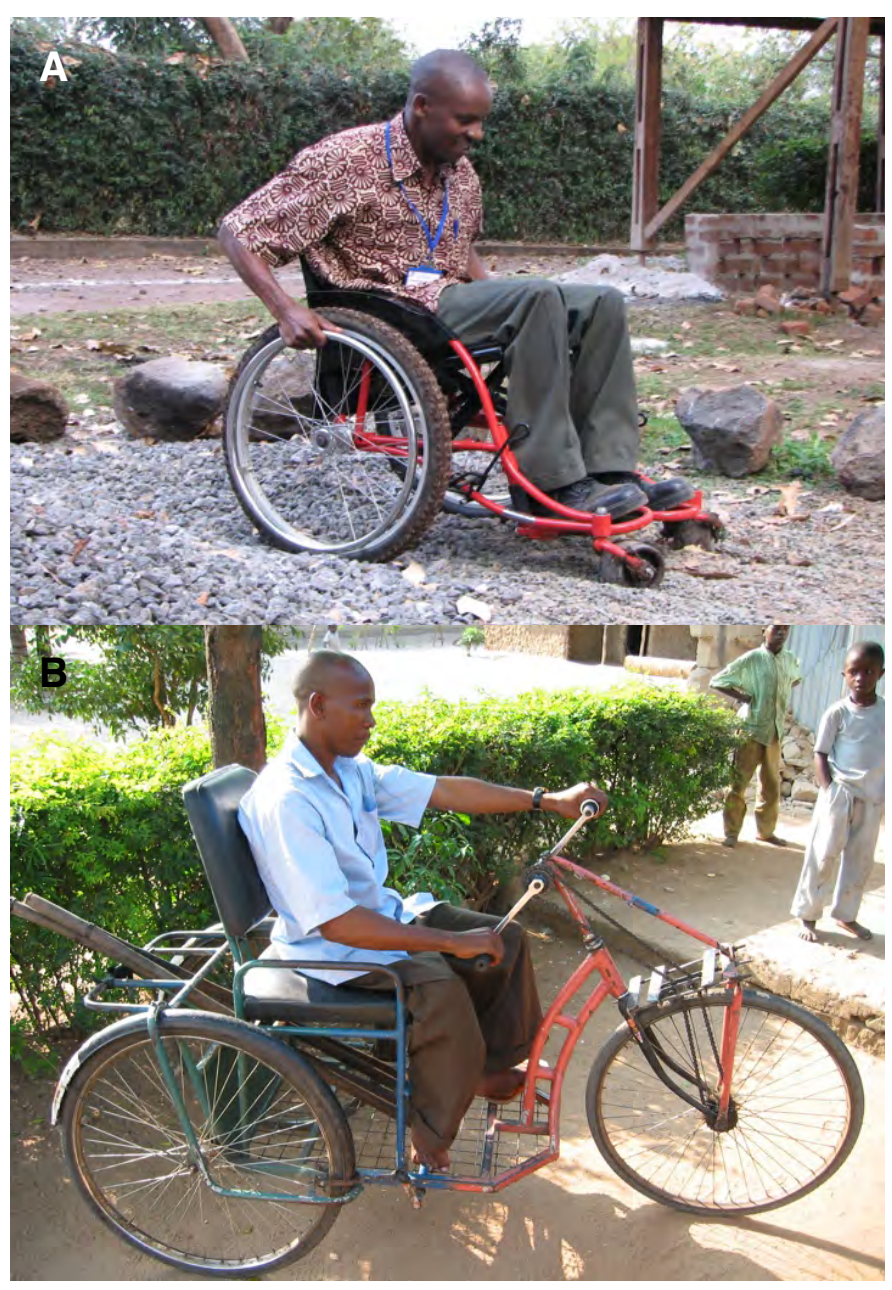

FIGURE 1. COMMONLY AVAILABLE MOBILITY AIDS IN DEVELOPING COUNTRIES. A) Conventional-style wheelchair. The user propels the wheelchair by grasping and pushing the pushrims attached to the wheels. B) Hand-powered tricycle. The user propels the tricycle via a hand crank system that drives either the front (shown) or rear wheels.

ficient to propel than a wheelchair [1,4],5], but are difficult to maneuver on soft ground and up steep hills, and are much too large to use within the home. There is tremendous demand for a device like the LFC, as 70 percent of the 20 to 40 million people in the developing world who require a wheelchair live in rural areas [6, 7, 8], where rough roads and muddy walking paths often provide the only connection to community, employment, and education.

This paper presents the evolution and validation of the LFC design through three user trials in East Africa, Guatemala, and India. The LFC project is an example of stakeholder-driven design, in that our partners in developing countries did not simply articulate their needs; they participated in the entire design pro- cess to identify and create solutions as well. The technology was directed towards a viable solution by engaging stakeholders that represent each link in the chain from inception of the LFC idea to implementation in the real world. Survey and biomechanical data from test subjects were used to identify strengths, weaknesses, and ideas for revision of the LFC, as well as show its improvement in performance on various terrains after successive iterations of the design. The trials included subjects who use a variety of mobility aids; since the LFC is designed to provide mobility to those who need the seating and postural support of a wheelchair, the results presented in this paper compare the performance of the LFC to conventional, pushrim-propelled wheelchairs. Data comparing the LFC to hand-powered tricycles are not included in this paper because tricycles cannot be used indoors and require balance and torso strength, which many wheelchair users, particularly spinal cord injury patients, do not have.

The paper concludes with a discussion about how the LFC is a "constraint-driven innovation." This concept connects the theories of "disruptive innovation" [9] and "reverse innovation" [10] to describe how technologies can be created to offer high levels of performance at low cost in the developing world, and that have market potential in the rich world. The process and graphical representation of constraint-driven innovation presented in this paper may be used as a design tool to help engineers leverage constraints faced in developing countries to create technologies that have global value.

\section{LFC TECHNOLOGY}

Instead of using multiple gears to change speed, an LFC user varies mechanical advantage by sliding his or her hands up and down the levers (Fig. 2). Pushing forwards on the levers propels the chair through a single-speed bicycle chain drive; pulling back ratchets the drivetrain and resets it for the next stroke. Pulling all the way back engages the brakes, which are the small bars that protrude from the levers and rub against the tires. Human power and force output capabilities were used to determine a lever size and drivetrain geometry that enables the user to efficiently travel on smooth surfaces and gentle grades, and produce enough torque to overcome harsh terrain [11,12].

Varying mechanical advantage by changing the user's geometry (hand position on the levers), rather than the machine's geometry, enables the LFC drivetrain to be composed of a lightweight, single gear ratio chain drive made from bicycle components that cost less than \$20 USD and are found anywhere in the developing world [13]. The LFC drivetrain provides a 3:1 change in mechanical advantage; to put this performance/cost ratio into perspective, Shimano XTR mountain bike components, the company's top model, provide a 6:1 change in mechanical advantage but cost more than $\$ 1500$ USD [14, 15]. The overall cost of the LFC, produced in India and shipped anywhere 


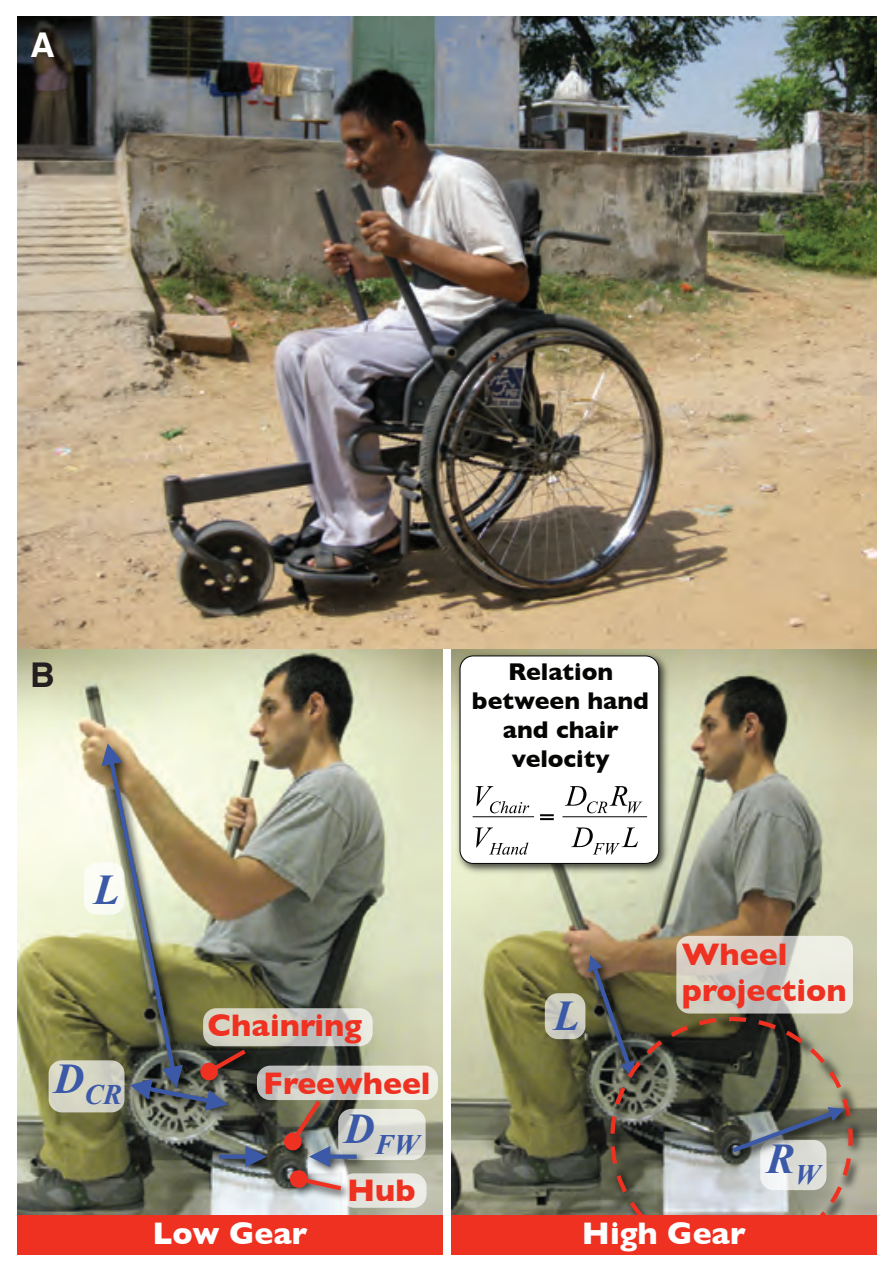

FIGURE 2. THE LEVERAGED FREEDOM CHAIR (LFC). A) An Indian trial subject using the LFC in his home village. B) LFC variable mechanical advantage, single speed drivetrain. All components in the drivetrain are made from single-speed bicycle parts found anywhere in the developing world. Inset gives the mathematical relationship for how the ratio between LFC speed $\left(V_{C h a i r}\right)$ and pushing speed on the levers $\left(V_{H a n d}\right)$ varies as a function of the effective lever length $(L)$, which is determined by hand position on the levers. Other labels: diameter of the chainring $\left(D_{C R}\right)$, diameter of the freewheel $\left(D_{F W}\right)$, and rear wheel radius $\left(R_{W}\right)$.

in the world, is \$200 USD. This price point is within the same range of the most commonly distributed wheelchairs in developing countries [16, 17, 18, 19] and is 25 to 30 times less expensive than off road wheelchairs with similar capabilities offered in the rich world [20, 21, 22]. The current version of the LFC weighs $21.4 \mathrm{~kg}$ (47 lbs), which is within $2.3 \mathrm{~kg}$ (5 lbs) of other manual wheelchairs offered in the developing world. For indoor use, the levers on the LFC can be removed and stowed in the frame, which converts the chair to a regular, pushrim-propelled wheelchair. All moving parts on the LFC are made from bicycle components, which make the chair repairable by local bicycle technicians commonly found in rural and urban areas of developing countries.

\section{MATERIALS AND METHODS User Trials of the LFC}

Each trial was conducted in partnership with a local developing country wheelchair manufacturer/distributor. Clients of these organizations, who are users of conventional wheelchairs or hand-powered tricycles, were asked to participate in the trials. Each trial subject was required to have a working mobility aid to use in the event that the LFC became inoperable, unsafe, or uncomfortable. Subjects participated in the trials at their own free will and were encouraged to use the LFC as much as possible but were not required to meet a usage quota. Each was allowed to keep their LFC, free-of-charge, at the end of the trial. All trials were approved by MIT's institutional review board as well as those of the respective local partner organizations.

All of the trials followed a similar format, wherein each subject was given an LFC to use for an extended period of time. At the culmination of the trial, subjects underwent biomechanical testing and were surveyed to provide input on strengths and weaknesses of the LFC design, as well as brainstorm possible upgrades. An important facet of conducting these interviews was establishing a good rapport and mutual respect with the subjects; each was told that he or she had invaluable knowledge about what it is like to be a mobility aid user in the developing world and that this knowledge was critical to ensuring that the LFC became a viable and successful product. We stressed that combining our knowledge - considering engineering, manufacturing, distribution, economic, social, and usage factors - we could create something together that none of us could alone. Appreciating the value of all participants' roles in the project, independent of citizenship and educational level, was critical in acquiring honest feedback and encouraging the trial subjects to articulate design solutions, as well as requirements and constraints.

East Africa Trial. Six LFC prototypes were produced with our partner, the Association for the Physically Disabled of Kenya in Nairob 1 . One chair was tested in Tanzania, one in Uganda, and the remaining four in Kenya. Members from our team trained the subjects how to use the LFC. The trial ran from August 2009 to January 2010. Three of the subjects (2 women and 1 man) were active wheelchair users, in that they could propel themselves without assistance, one was a wheelchair user (woman) who needed assistance with propulsion, and two were

1 http://www. facebook.com/pages / Association-for-the-Physically-Disabled-of-kenya/ 195906443764390 
full time hand-powered tricycle users (both men). Only data from the three active wheelchair users are presented in this paper. Biomechanical data for the East Africa trial are not included in this paper because the acquisition system used for the subsequent trials was not yet operational at the time of testing.

Guatemala Trial. Twelve LFC prototypes, upgraded from the East African design, were designed and produced with our partner, the Transitions Foundation of Guatemala in Antigue 2 Design input was also contributed by two of our East African trial subjects. The prototypes were given to twelve active Guatemalan wheelchair users. The trial ran from November 2010 to January 2011. Five of the subjects were Transitions staff (all men) who compared the LFC to a hospital-style wheelchair in the trial. The remaining seven subjects were clients of the Foundation ( 3 women and 4 men). The clients were not trained how to use the LFC when they received it; as such, their results are not included in this study because their proficiency using the LFC varied greatly and they were not able to fairly benchmark the LFC against their current wheelchairs.

India Trial. Twenty five LFC prototypes, upgraded from the Guatemala design, were produced with Pinnacle Industries of Indore ${ }^{3}$ and distributed to patients throughout India through Bhagwan Mahaveer Viklang Sahayata Samiti (BMVSS) ${ }^{4}$ commonly known as Jaipur Foot. Transitions, Pinnacle, and BMVSS participated in the redesign of the chair. BMVSS was sought as a partner on our project because it is the largest disability organization in the world in terms of providing assistive devices [23] and can scale distribution of the LFC. The trial ran from June 2011 to October 2011. Twelve of the subjects were active users of hospital-style wheelchairs ( 2 women and 10 men) and thirteen were hand-powered tricycle users (3 women and 10 men). Data from the tricycle users are excluded from this paper. After the trial, our team was able to follow up with eight (1 woman, 7 men) of the wheelchair users, seven of whom underwent biomechanical testing (1 woman, 6 men) and whose data are included in this paper.

\section{Biomechanical Testing}

Each test subject who underwent biomechanical testing rode their conventional wheelchair and the LFC on terrain that was representative of their home environment and for a distance that was representative of a daily commute. Each device was ridden for the same distance, following the same path. The subjects chose the distance to travel and were requested to maintain a pace that would not require stopping for rest, although rest stops were

\footnotetext{
http://www.transitionsfoundation.org

3 http://www.pinnacleindustries.com

http://www.jaipurfoot.org
}

permitted when required. When rest stops were taken, the time spent resting was included in the overall time of the test, which was used to calculate the average velocity results reported in this work.

In each test, subjects were instrumented with a data acquisition (DAQ) system to collect biomechanical data. When attached to the LFC, the system measures forward/back and side/side pushing force on the levers, hand position on the levers, angular displacement of the levers, speed of the chair, inclination and side slope angle, heart rate, and oxygen consumption rate (VO2). VO2 is commonly used to measure physical exertion during wheelchair tests [24,25]. When attached to a wheelchair, the system measures speed of the chair, inclination and side slope angle, heart rate, and oxygen consumption rate. Velocity and VO2 are the parameters reported in this paper.

The DAQ system was custom designed for the harsh conditions experienced during testing in developing countries, and because an off-the-shelf, portable system would have cost approximately $\$ 10,000$ USD [26]. The DAQ box is based on two 10 bit, 8 channel acquisition boards that record at $100 \mathrm{~Hz}$ [27]. Velocity is measured by counting rotations in time of the rear wheel of the LFC/wheelchair and knowing the wheel's diameter. Oxygen consumption is measured through a custom-made VO2 mask based on a mask from a constant positive airway pressure system, used to treat sleep apnea. All vents in the mask are sealed and the main inlet/outlet tube feeds into an oxygen concentration sensor [29] and a spirometer [28], which measures flow rate of the air breathed in and out.

Each subject's maximum attainable propulsion force using the LFC and his or her conventional wheelchair was measured. This was accomplished by connecting a force scale between the wheelchair/LFC and an immobile object and having the subject produce the highest static pulling force possible with each device. The connection point on the chair was chosen to be as close to the ground as possible, to minimize moments placed on the chair frame that could tip the subject backwards. Tests of both chairs for each subject were always conducted on the same ground type for consistency in traction.

\section{DESIGN EVOLUTION RESULTING FROM STAKE- HOLDER FEEDBACK \\ Design Upgrades Identified and Implemented}

Figure 3 shows the three iterations of the LFC design that were used in East Africa (Fig. 3A), Guatemala (Fig. 3B), and India (Fig. 3 C). Major design changes that resulted from stakeholder feedback are denoted. All six subjects in the East Africa trial said that the LFC was too wide to fit through a standard doorway and that none of them used the chair indoors. This feedback made our team realize that the LFC had to be a viable conventional wheelchair when the levers are removed, as the levers would typically be used only for an hour or two per day dur- 
ing long distance travel. The second concern about the design, raised by five of the East African test subjects, was that the LFC tipped backwards too easily and felt precarious when going up hills. The final problem, agreed on by the subjects and our team, was that the LFC was too heavy; at $30 \mathrm{~kg}$ (65 lbs), it was at least $9.1 \mathrm{~kg}(20 \mathrm{lbs})$ heavier than other developing world wheelchairs on the market.

The Guatemala LFC (Fig. 3B) was designed to rectify the issues raised in the East African trial. The width of the chair was reduced by $8.9 \mathrm{~cm}$ (3.5 in), making it $68.6 \mathrm{~cm}$ (27 in wide), which is approximately $1.3 \mathrm{~cm}(0.5 \mathrm{in})$ narrower than a hospital chair of the same seat size. This was accomplished by tapering the seat (Fig. 3B inset a), making it wide at the hips and narrower at the front to allow clearance for the levers. Putting jogs in the levers (Fig. 3 $\mathrm{B}$, inset $\mathrm{b}$ ) enabled the drivetrain to be set closer to the frame, which narrowed the stance of the chair. Finally, $4.4 \mathrm{~cm}$ (1.75 in) wide tires replaced the $6.4 \mathrm{~cm}$ (2.5 in) wide mountain bike tires that were used on the East African chair.

Backwards tipping stability was improved on the Guatemala LFC by lowering the center of gravity by $12.7 \mathrm{~cm}(5 \mathrm{in}) \mathrm{com}-$ pared to the East African version; $10.2 \mathrm{~cm}$ (4 in) resulted from a change in frame geometry and the additional $2.5 \mathrm{~cm}$ (1 in) was gained from switching to 24 in rather than 26 in wheels. A back pad (Fig. 3B, box c) was also added to help tipping stability. This pad acts like a bench press bench; it provides a reaction force against the user's spinal column when he or she pushes on the levers. In the East Africa LFC, users' upper torso would bend backwards over the top of the seat and shift their center of gravity backwards when the levers were pushed. The back pad keeps the spinal column straight and the center of gravity stationary.

The mass of the Guatemala LFC is $20.4 \mathrm{~kg}$ (45 lbs), $9.1 \mathrm{~kg}$ (20 lbs) lower than that of the East Africa chair. This was accomplished through changing the chain tensioning/seat adjustment system. The East Africa chair has heavy bolt plates to which the wheels affix. The Guatemala chair uses a lighter clamp system where the upper seat frame, which contains the lever pivots, clamps onto the lower frame, which contains the wheel bearings; sliding the frames relative to each other tensions the chains and adjusts forward/aft seat position. Steel volume in the seat frame was also reduced by using $1.9 \mathrm{~cm}$ (0.75 in) rather than $2.5 \mathrm{~cm}$ (1 in) diameter tubing.

Following the development of the Guatemala LFC, Transitions experimented with adding straps to the chair to restrain movement of the rider's torso and feet. Many subjects in the trial, particularly those who had sustained a spinal cord injury, liked the security offered by the straps, particularly when going down hill and pulling on the levers to apply the brakes. Three of the twelve subjects requested that straps be standard in future versions of the chair. Five test subjects suggested that the parking brakes be moved to a new position. When using the pushrims, the parking brakes could pinch the rider's thumbs against the tires. The levers also tended to hit the parking brakes, limiting their
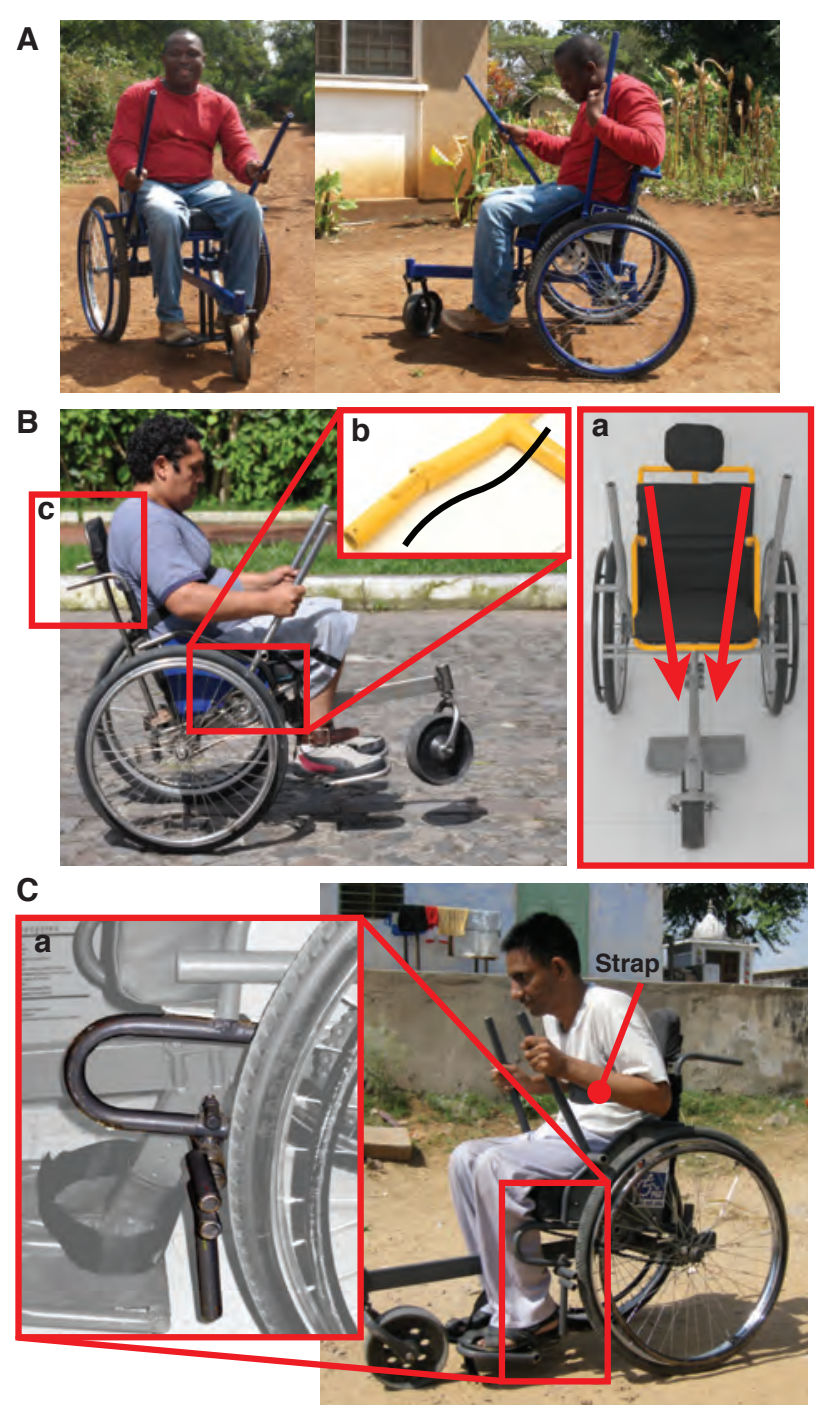

FIGURE 3. DESIGN CHANGES TO THE LFC THROUGH THREE USER TRIALS. A) Trial subject in East Africa. B) Trial subject in Guatemala. This version of the LFC was narrowed by $8.9 \mathrm{~cm}$ (3.5 in) compared to the East Africa version by tapering the arm rests to make the seat wider at the hips and narrower at the front (inset a, relevant sections of frame in color, tapering of seat denoted by arrows), to allow swing clearance for the levers, and by jogging the ends of the levers to position the drivetrain closer to the seat frame (inset $b$, jog shape denoted by black, s-shaped line). To prevent tipping backwards, the center of gravity of the LFC was lowered by $12.7 \mathrm{~cm}$ (5 in) and a pad was added to the seat back (box c) to maintain correct spinal posture and provide a reaction force when pushing on the levers. C) Trial subject in India. The parking brakes were lowered compared to those on the Guatemala LFC to increase the maximum angular swing of the levers (inset a, parking brake and frame shown in color). Chest, waist, and foot straps were added to improve security of the user (chest strap shown). 
stroke, when propelling the LFC at high speeds. The most common suggestion voiced in the Guatemala trial, which was made by six of the seven people whose results are excluded from this paper because they were not trained how to use the LFC, was that recipients of an LFC should be trained how to use it.

The India LFC (Fig. 3C) was designed to address the critical feedback voiced by subjects in the Guatemala trial. A chest, waist, and foot strap made of Velcro were added as standard features to the chair. The parking brakes were lowered by 12.7 $\mathrm{cm}$ (5 in) to allow for a larger stroke while still preventing the levers from hitting the ground in the event they are dropped by the user (Fig. 3 $\mathrm{C}$, inset a). The new position of the parking brake mechanism is outside the hand stroke path when using the pushrims, which mitigates the risk of catching the user's thumbs between the brakes and the tires. A training program was implemented when the India LFCs were distributed. Each subject received more than two hours of instruction, including skills to cope with obstacles, before he or she brought the chair home. The assumption that patients can receive training when receiving an LFC is a reasonable one, as the World Health Organization's "Guidelines for the Provision of Manual Wheelchairs in Less-Resourced Settings" includes training as a critical part of appropriate wheelchair provision [8].

The most common feedback following the India trial, voiced by seven of the subjects, was that the LFC should have cargo space either under or behind the seat. Storage bags will be incorporated into the production version of the chair.

\section{Measuring Efficacy of Design Upgrades}

Figure 4 shows aggregated survey data from the three trials, comparing the performance of the LFC to conventional wheelchairs in different terrains [30]. In the East Africa Trial (Fig. 4A), the LFC's deficiencies indoors, and advantages on rough terrain, are apparent. The low indoor score is consistent with feedback about the chair's width preventing it from fitting through doorways and being used indoors.

In the Guatemala trial (Fig. 4B), the LFC's reduced width compared to the East Africa chair resulted in a significantly higher score for indoor mobility, while still maintaining an advantage on outdoor terrain.

Feedback gathered after the India trial is the most compelling of the three. Figure $4 \mathrm{C}$ shows that the LFC provides drastically better performance on rough terrains compared to a conventional wheelchair with little to no compromise in indoor mobility.

\section{RESULTS OF BIOMECHANICAL TESTS}

Results from the Guatemala and India trial showing velocity and efficiency when traveling on a representative daily commute using both the LFC and a conventional wheelchair are given in
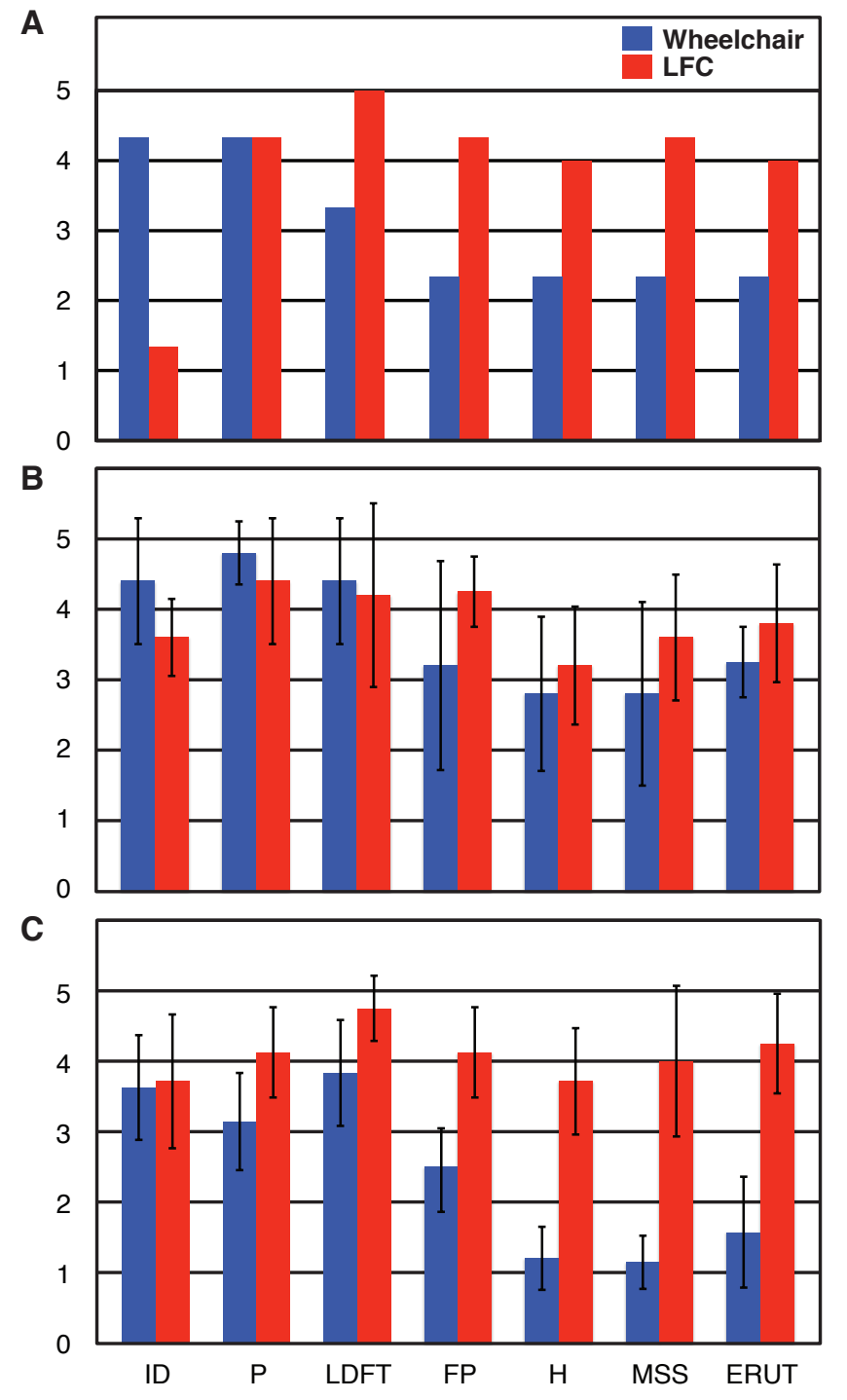

FIGURE 4. SUBJECT-AVERAGED SURVEY DATA ABOUT THE LFC'S PERFORMANCE ON VARIOUS TERRAINS FROM THREE TRIALS. A) East Africa trial $(n=3)$. B) Guatemala trial $(n=5)$. C) India trial $(n=8)$. Subjects rated the performance of their conventional wheelchair and the LFC on a 1 to 5 scale, with 1 being very bad to 5 being very good. Error bars denote \pm s.d. Labels: indoors (ID), pavement (P), long distance on flat terrain (LDFT), footpaths (FP), hills (H), muddy and sandy soil (MSS), and extremely rough and uneven terrain (ERUT). These data demonstrate how the evolution of the LFC design resulted in improved indoor performance and superior rough terrain performance compared to a conventional wheelchair.

Fig. 5 [30]. Efficiency is reported as velocity divided by $\mathrm{VO} 2$, which is a benefit/cost ratio in that high speed at a low metabolic cost is desirable. Note that the data are reported as a function of position along the course, not as a function of time. This is 
to show how both devices perform when traveling over the same terrain.

These data show that the LFC provides a significant performance advantage over a conventional, hospital-style wheelchair when traveling on developing country terrain. In true average velocity, determined by total distance traveled and total time of each test, the mean velocity of the LFC in Guatemala was 1.14 $\mathrm{m} / \mathrm{s} \pm 0.19 \mathrm{~m} / \mathrm{s}$, with the wheelchair averaging $0.63 \pm 0.14 \mathrm{~m} / \mathrm{s}$ (mean \pm s.d.). In India, the LFC averaged $0.91 \pm 0.18 \mathrm{~m} / \mathrm{s}$; the wheelchair averaged $0.60 \pm 0.23 \mathrm{~m} / \mathrm{s}$ (mean \pm s.d.). Overall, the LFC provided the subjects with an average increase in velocity of 76 percent compared to the conventional wheelchair.

The LFC tested 59 percent more efficient than the wheelchair in Guatemala (Fig. 5B) and 28 percent more efficient in India (Fig. 5D) (calculated from velocity and VO2 as a function of position, not time). The combined average increase in efficiency for both tests was 41 percent.

In the peak propulsion tests, the LFC was able to generate $565 \pm 95 \mathrm{~N}$ with the wheelchair able to produce $383 \pm 51 \mathrm{~N}$ (mean \pm s.d.). In India, the measurements were $461 \pm 84 \mathrm{~N}$ for the LFC and $301 \pm 39 \mathrm{~N}$ (mean \pm s.d.) for the wheelchair. Subjects' average increase in peak propulsion force using the LFC instead of a conventional wheelchair, calculated over both tests, was 51 percent.

\section{STAKEHOLDER-DRIVEN INNOVATION}

Using stakeholder input to drive the evolution of the LFC resulted in improved performance with each iteration of the design. The impact of design upgrades (Fig. 3) were reflected in the positive changes in survey feedback in subsequent trials (Fig. 4), with the India LFC offering comparable indoor performance to a conventional wheelchair with far superior outdoor capabilities. Furthermore, the number and complexity of requested design revisions decreased with every trial; the relatively minor requests for upgrades following the India trial indicated that the LFC design was sound and ready for commercialization. At the time of writing this paper, approximately 100 LFCs had been delivered and Pinnacle Industries, our production partner in India, was tooled up to make $500 \mathrm{LFCs} /$ month. India was chosen as the first production location for the LFC in order to leverage the large distribution network through BMVSS and because there are no other low-cost, off road wheelchairs currently available in the country. The LFC will go on sale to anyone in early 2013.

The LFC would not have come to fruition without the active participation of all the stakeholders related to the technology. The inner circle in Fig. 6 demonstrates the stages through which a technology matures, from innovation to dissemination in the real world. Certain stakeholders have skills most relevant to advancing each stage, represented by the outer circle. The LFC successfully came to market because each stakeholder in the circle was represented in the project and had the opportunity
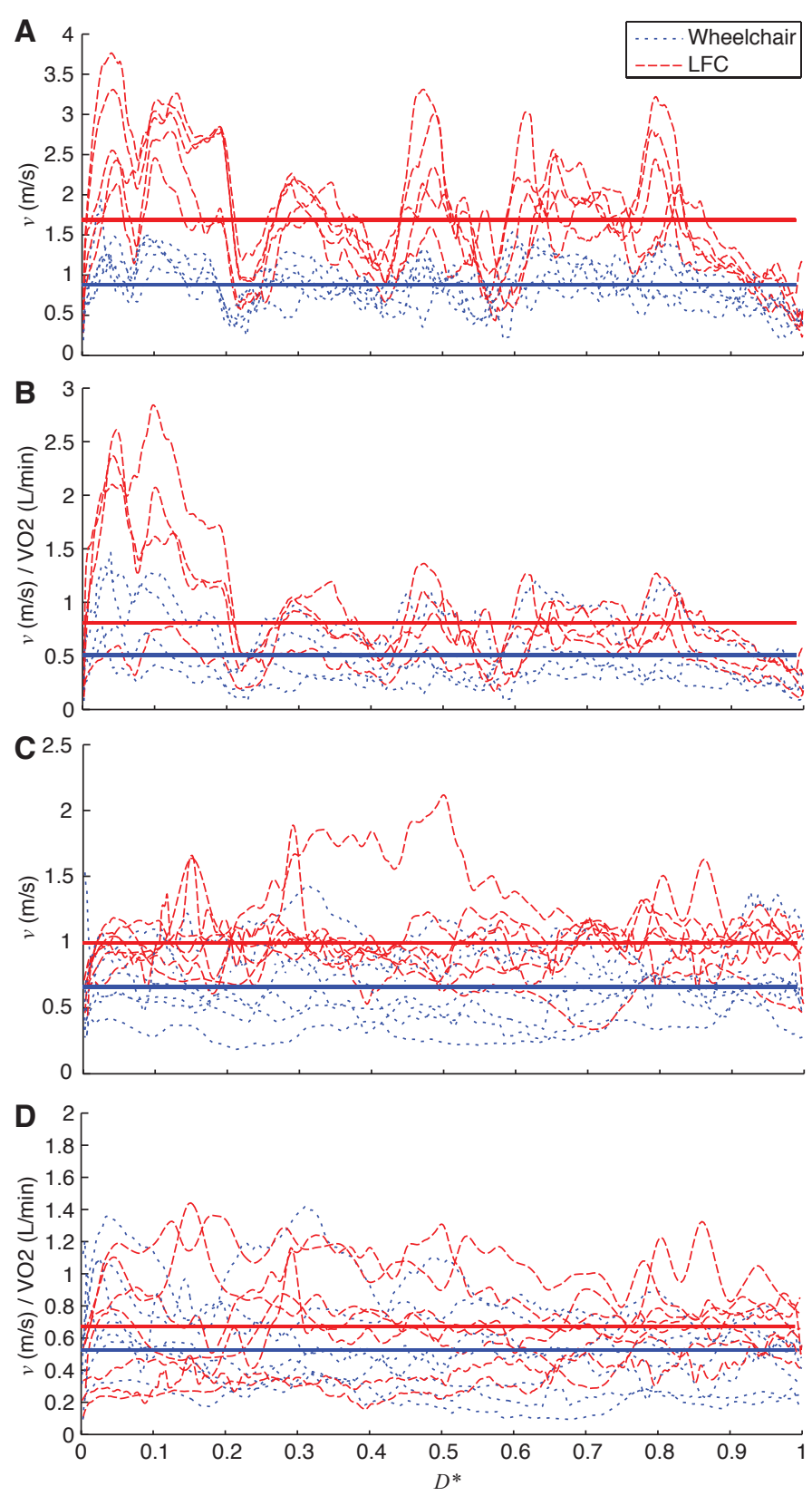

FIGURE 5. BIOMECHANICAL DATA COMPARING LFC PERFORMANCE TO THAT OF CONVENTIONAL WHEELCHAIRS. A) Velocity data for Guatemala $(n=5)$. B) Efficiency data for Guatemala ( $=4 ; \mathrm{VO} 2$ data was not recorded for one subject). C) and D) Velocity and efficiency data for India $(n=7)$, respectively. Solid lines denote average values for all subjects in the trial, calculated as a function of position along the test course. Efficiency is defined as a benefit/cost ratio, $\frac{v}{\mathrm{VO} 2}$, as high velocity $(v)$ for a low metabolic cost (VO2) is desirable. Data are plotted versus non dimensional distance, $D^{*}=\frac{\text { distance traveled }}{\text { total distance }}$, as to normalize all test lengths, independent of actual distance. 
to contribute requirements, constraints, and insight necessary for completing the cycle. This development process, including identifying customer and stakeholder needs, is similar to commonly accepted product design practices [31], with a few notable exceptions.

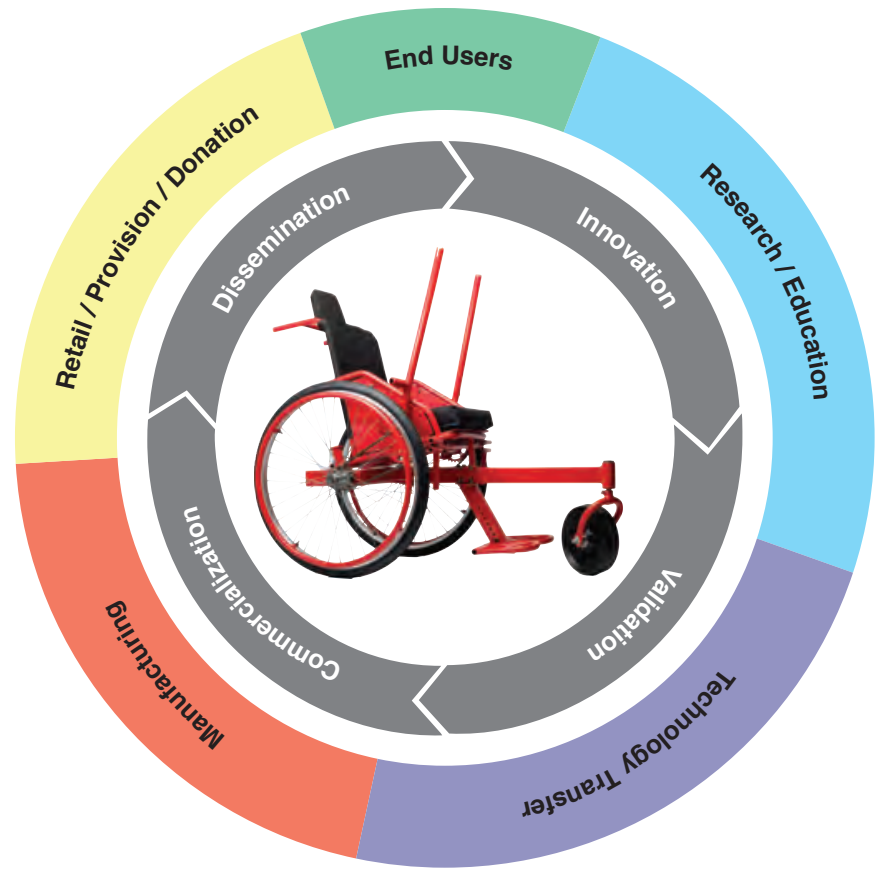

FIGURE 6. STAKEHOLDER-DRIVEN INNOVATION CYCLE BEHIND THE LFC. The inner circle represents the stages of development for the LFC as it matured from inception to implementation in the real world. The outer circle represents the stakeholders required to bring the LFC to fruition, positioned relative to their primary contributions in the development stages. The cycle starts and ends with end users.

Representatives from each stakeholder group in the outer ring of Fig. 6 were engaged from the beginning of the project. This enabled our team to understand the most important constraints and requirements associated with an improved rural area mobility aid: end users expressed their latent needs of being able to travel long distances on rough terrain and navigate tight, indoor confines; manufactures added design elements to improve production and identified that custom parts are difficult to repair/replace in the field, which we solved with the usage of bicycle components; and wheelchair distributors set the price point of $\sim \$ 200$, which would make the LFC competitively priced, and the same cost to donors, compared to other wheelchairs on the market. If these design requirements were elucidated in a linear fashion, many more iterations may have been required to understand and achieve the necessary per- formance/manufacture/repairability/cost design specifications of the LFC.

Also unique in Fig. 6 are the positions of academics and technology transfer firms. Being from academia, our team had the resources to innovate, test, and iterate quickly. But the products of academic projects are typically proof-of-concept prototypes, not products ready for commercialization. To bridge the gap between academia and industry, it was necessary to form a start-up, Global Research Innovation and Technology (GRIT) and engage the help of a product development firm, Continuum 6 These stakeholders were able to do tasks, not academic in nature but critical to bringing a product to market, such as design for manufacturing, quality control, and packaging.

The final point about Fig. 6 is that the cycle starts and ends with end users; they understand their own lives best and are thus in the best position to articulate a need and validate a solution. Navigating differences in culture, demographics, and geography can be tricky, but it is imperative that engineers creating technologies for developing countries and emerging markets do so. They need to recognize end users, as well as all the other stakeholders of a technology, as collaborators in order to successfully marry the technical and socioeconomic factors that are critical to creating an appropriate solution.

\section{CONSTRAINT-DRIVEN INNOVATION}

Due to the highly-constrained environment for which the LFC was developed, a novel solution was required to meet the price and performance requirements of rural area wheelchair users in developing countries. This result became obvious when we inspected the current wheelchair market, shown with the existing technology (ET) curve in Fig. 7. This market is composed of three categories. The first is wheelchairs designed specifically for distribution in developing countries (Fig. 7, box a), which include ultra-low-cost, hospital-style chairs [17,16] and low-cost wheelchairs that are designed to handle rugged use [19, 18]. The second category includes wheelchairs that are commonly sold in the US (Fig. 7. box b), which typically range from $\$ 500$ to \$2000 [32], as well as ultralight manual wheelchairs from the manufacturers that represent 65 percent of the ultralight market [33, 34, 35]. The third category represents wheelchairs designed specifically to go off road (Fig. 7], box c) [20, 21, 22].

Our team saw that the appropriate solution for rural area mobility in developing countries must lie below the ET curve in Fig. 7 and offer comparable levels of performance as high-end, off road chairs in the rich world (Fig. 77, line 1) but be sold at a similar price point as other developing world wheelchairs (Fig. 7 . line 2). These constraints drove innovation (Fig. 7, CDI arrow), resulting in a new cost-performance curve and the creation of a

http://gogrit.org/

http://continuuminnovation.com/ 

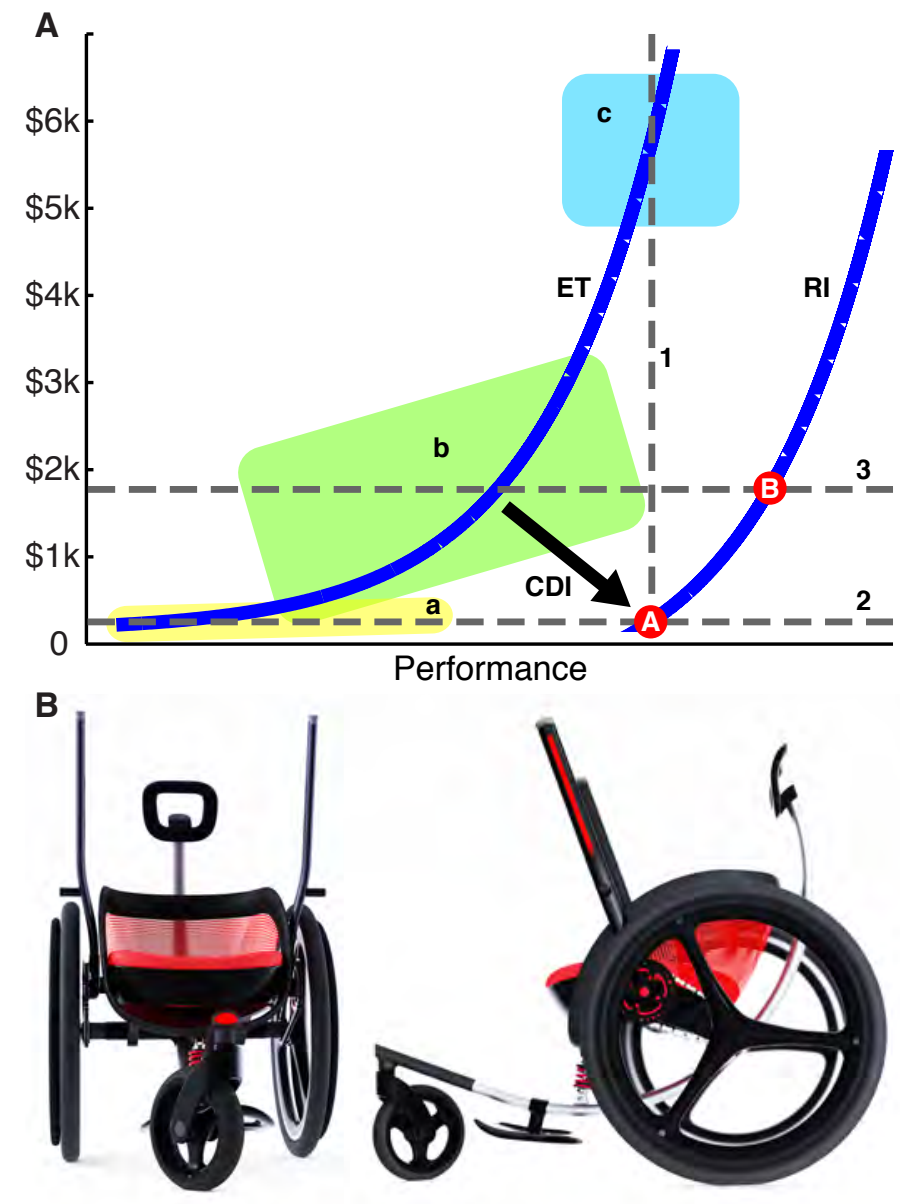

FIGURE 7. CONSTRAINT-DRIVEN INNOVATION. A) Cost vs performance curve for existing and LFC-based wheelchair technologies. Performance is judged on a relative scale, from the standpoint of products' design attributes and capability to navigate the varied terrains of developing countries. The existing technology (ET) curve represents currently available wheelchairs: those distributed in developing countries (box a); rich-world manual wheelchairs (box b); and high-end, off road wheelchairs (box c). Line 1 denotes the performance constraint for a rural area wheelchair. Line 2 shows the cost constraint for wheelchairs sold in the developing world. Constraint-driven innovation (CDI arrow) resulted in the creation of the LFC (point A), as no products on the ET curve could offer the necessary performance and price point. Point A lies on the reverse innovation (RI) curve, which indicates the potential to adapt the technology to new, wealthier markets. Point B demonstrates a market opportunity in the rich-world for the LFC at a price point equivalent to existing products (line 3). B) Rendering of a rich world LFC prototype that corresponds to point $\mathrm{B}$.

disruptive innovation (Fig. 7, point A), which is a technology initially aimed at lower-value or new markets but that provides unique attributes that may position it to be competitive in estab- lished markets [9].

The new cost-performance curve enabled us to predict how LFC technology could penetrate wealthier markets through reverse innovation (Fig. 7, RI curve), which is the process of creating technologies for developing/emerging markets that offer a high level of performance for a low cost compared to their rich world equivalents, and then leveraging these attributes to create new global market opportunities [10]. We realized that by adding desirable features to the LFC at an additional cost, such as improved aesthetics and lower weight, we could move up the RI curve in Fig. 7 and provide a high-performance product (Fig. 7 , point B) at the same price point as existing active wheelchairs (Fig. 7, line 3). We are currently designing a rich world embodiment of the LFC around these cost/performance metrics (Fig. $7 \mathrm{~B})^{7}$.

\section{CONCLUSIONS}

This paper presents the design evolution of the Leveraged Freedom Chair (LFC), a novel, lever-propelled mobility aid created for rural areas of developing countries. Biomechanical data presented in this paper demonstrate the effectiveness of the LFC variable mechanical advantage lever drivetrain. The LFC consistently and conclusively out-performed conventional, hospitalstyle wheelchairs in speed, efficiency, and propulsion force during field trials in Guatemala and India. Using stakeholder input to drive the evolution of the LFC resulted in improved performance with each iteration of the design. The upgrades shown in Fig. 3 were reflected in the positive changes in survey feedback in subsequent trials (Fig. 4), with the India LFC offering comparable indoor performance to a conventional wheelchair with far superior outdoor capabilities. Furthermore, the number and complexity of requested design revisions decreased with every trial; the relatively minor requests for upgrades following the India trial indicated that the LFC design was sound and ready for commercialization.

A valuable lesson learned in this project was the power of engaging all stakeholders in the product innovation cycle, who represent each link in the chain from inception of an idea to implementation in the real world (Fig. 6). Each stakeholder asserted unique constraints and requirements on the design. Through their input, we were able to understand the price and performance characteristics necessary for a successful product, as well as design for manufacture, repair, and large-scale distribution. Together we were able to produce much more than any single group could have alone. When creating technology for developing countries and emerging markets, engineers must recognize stakeholders as collaborators and give them the opportunity to articulate problems and solutions. It was particularly important that end users represented the beginning and the end

\footnotetext{
${ }^{7}$ Rendering by Jake Childs and Jung Tak, Continuum
} 
of the LFC development cycle; they were in the best position to articulate the mobility challenges in their own lives, and they were the most qualified to judge the efficacy of a solution.

The idea of constraint-driven innovation (Fig. 7) is a novel explanation of how constraints placed on technologies created for developing/emerging markets can lead to disruptive innovations, which through reverse innovation can be adapted to wealthy and poor markets. Constraint-driven innovation was critical in the LFC project, as it enabled our team to understand that a viable mobility solution for rural areas in developing countries had to offer a higher level of performance at a lower cost than could be obtained with existing technology. This realization led to the creation of a wheelchair with comparable weight and cost as others on the market, but that delivers superior rough terrain performance because of its innovative lever drive. Achieving these design metrics opened up new market opportunities for the LFC in the rich world. The graphical representation in Fig. 7 enabled our team to visualize market opportunities and design requirements of the LFC in both the developing and developed world. Constraint-driven innovation may be a catalyst for new ideas and a valuable design tool for other engineers creating technologies for global markets.

\section{ACKNOWLEDGMENTS}

This work was sponsored by the Singapore University of Technology and Design, the Inter-American Development Bank, the National Collegiate Inventors and Innovators Alliance, the MIT D-Lab program, the Clinton Global Initiative, the Hugh Hampton Young Memorial Fellowship, the MIT Department of Mechanical Engineering, the MIT Public Service Center, the MIT IDEAS Competition, the MIT Edgerton Center, the MIT UROP program, Battelle India, and ARB. Members of the LFC team include Natasha Scolnik, Mario Bollini, Benjamin Judge, Harrison O'Hanley, Prof. Sudipto Mukherjee, and Prof. Daniel Frey. Collaborators on the LFC project include Global Research Innovation and Technology (GRIT), Bhagwan Mahaveer Viklang Sahayata Samiti, Pinnacle Industries, Transitions Foundation of Guatemala, The Association for the Physically Disabled of Kenya, Whirlwind Wheelchair International, Continuum, KASI of Tanzania, and MADE of Uganda. Additional contributions to the project were made by Xuefeng Chen, Danielle Hicks, Nydia Ruleman, Daniel Dorsch, Alex Galvez, Joel Chiti, D.R. Mehta, Dr. M.K. Mathur, Dr. Pooja Mukul, Dr. Nimish Mittal, and Dr. Mrinal Joshi.

\section{REFERENCES}

[1] van der Woude, L., Dallmeijer, A., Janssen, T., and Veeger, D., 2001. "Alternative modes of manual wheelchair ambulation: an overview". American journal of physical medicine \& rehabilitation, 80(10), p. 765.
[2] Winter, V., Amos, G., et al., 2006. "Assessment of wheelchair technology in tanzania". International Journal for Service Learning in Engineering, 1(2).

[3] Personal conversations with mobility aid manufacturers and suppliers in Kenya, Tanzania, Uganda, the Philippines, Thailand, Vietnam, and India, 2005-2012.

[4] van der Woude, L., Botden, E., Vriend, I., and Veeger, D., 1997. "Mechanical advantage in wheelchair lever propulsion: effect on physical strain and efficiency". Journal of rehabilitation research and development, 34, pp. 286-294.

[5] van der Linden, M., Valent, L., Veeger, H., and van der Wonde, L., 1996. "The effect of wheelchair handrim tube diameter on propulsion efficiency and force application (tube diameter and efficiency in wheelchairs)". Rehabilitation Engineering, IEEE Transactions on, 4(3), pp. 123132.

[6] United States Agency for International Development, 2003. Annual Program Statement.

[7] Groce, N., 1999. "Health beliefs and behavior towards individuals with disability cross-culturally". Cross-cultural rehabilitation, An international perspective, pp. 37-47.

[8] Armstrong, W., Borg, J., Krizack, M., Lindsley, A., Mines, K., Pearlman, J., Reisinger, K., and Sheldon, S., 2008. Guidelines on the provision of manual wheelchairs in less resourced settings. World Health Organization.

[9] Christensen, C., 1997. The innovator's dilemma: when new technologies cause great firms to fail. Harvard Business Press.

[10] Govindarajan, V., and Trimble, C., 2012. Reverse Innovation: Create Far From Home, Win Everywhere. Harvard Business School Press.

[11] Winter, V, A., Bollini, M., DeLatte, D., O’Hanley, H., and Scolnik, N., 2009. "The Design and Testing of a Low-Cost, Globally-Manufacturable, Multi-Speed Mobility Aid Designed for Use on Varied Terrain in Developing and Developed Countries". In Proceedings of the ASME 2009 International Design Engineering Technical Conferences and Computers and Information in Engineering Conference, no. DETC2009-87609.

[12] Winter, V, A., Bollini, M., DeLatte, D., O’Hanley, H., Pearlman, J., and Scolnik, N., 2010. "The Design, Fabrication, and Performance of the East African Trial Leveraged Freedom Chair". In Proceedings of the ASME 2010 International Design Engineering Technical Conferences and Computers and Information in Engineering Conference, no. DETC2010-29096.

[13] Personal conversations with bicycle part retailers in Kenya, Tanzania, Guatemala, Vietnam, and India, 2005-2011.

[14] Shimano, 2012. XTR component product page. http: //bike.shimano.com/.

[15] Competative Cyclist, 2012. Shimano XTR Race Kit. http: / / www. competitivecyclist.com. 
[16] Wheelchair Foundation, 2013. Wheelchair Donation Cycle. http://www. wheelchairfoundation.org/ programs/wheelchair_cycle.

[17] Free Wheelchair Mission, 2013. The Story Behind the Chair. http://www. freewheelchairmission. org/site/c.fgLFIXOJKtF/b.6064389/k. 7203/The_Story_Behind_the_Chair.htm.

[18] Walkabout Foundation, 2013. Build a Wheelchair - The Whirlwind Roughrider. https:// walkaboutfoundation.org/wheelchair/ build-a-wheelchair.html.

[19] Motivation UK, $2013 . \quad$ Wheelchairs: Innovative Wheelchairs for All Terrain. http: //www.motivation.org.uk/our-products/ wheelchairs/

[20] Renegade Wheelchairs, 2013. Standard wheelchair order form. http://www.alphaonenow.com/ userfiles/renegade_orderform.pdf

[21] Mountain Trike, 2013. Buy a Trike. http://www. mountaintrike.co.uk/page/buy-a-trike.

[22] Trekinetic, 2013. K-2 All Terrain Manual Wheelchair. http://www.trekinetic.com/.

[23] Bhagwan Mahaveer Viklang Sahayata Samiti, 2007. What is our Progress? http://www.jaipurfoot.org/ 02_progress_performance.asp.

[24] Stroud, L., 2009. "Comparison of metabolic gas analysis between a standard laboratory system and a portable device”. Journal of Sports Science and Medicine, 8, pp. 491492.

[25] Hilbers, P., and White, T., 1987. "Effects of wheelchair design on metabolic and heart rate responses during propulsion by persons with paraplegia". Physical Therapy, 67(9), p. 1355.

[26] Qubit Systems, 2012. BBB1LP Breath by Breath Package $(\mathrm{O} 2+\mathrm{CO} 2)$ product page. http://qubitsystems . $\mathrm{Com}$.

[27] Sparkfun Electronics, 2012. Logomatic v2 Serial SD Datalogger product page. http://www.sparkfun.com/ products/8627.

[28] Vernier, 2012. Spirometer product information. http://www.vernier.com/products/ sensors/spr-bta/.

[29] Vernier, 2012. O2 sensor product information. http://www.vernier.com/products/ sensors/o2-bta/

[30] Winter, V, A., Bollini, M., Judge, B., Scolnik, N., O'Hanley, H., Dorsch, D., Mukherjee, S., and Frey, D., 2012. "Stakeholder-Driven Design Evolution of the Leveraged Freedom Chair Developing World Wheelchair". In Proceedings of the ASME 2012 International Mechanical Engineering Congress \& Exposition, no. IMECE201288881 .
[31] Ulrich, K., and Eppinger, S., 2012. Product Design and Development, 5 ed. McGraw-Hill/Irwin.

[32] CostHelper.com, 2013. How Much Does a Wheelchair Cost. http://health.costhelper.com/ wheelchair.html.

[33] Frost \& Sullivan, 2002. North American Mobility Aids Markets. Market research report.

[34] Sunrise Medical, 2013. Quickie Adult Manual Rigid Wheelchairs. http://www. sunrisemedical.com/products/product_ list.jsp?FOLDER3C3Efolder_id= $2534374302128425 \&$ ASSORTMENT:3C\% 3East_id=1408474395285139\&bmUID $=$ 1358498961269\&theFolderID= 2534374302128425 .

[35] Invacare, 2013. Top End Everyday Chairs. http: //www.invacare.com/cgi-bin/imhqprd/ inv_catalog/prod_cat.jsp?s=0\&catOID= $-536885323$. 